\title{
Egg shell ultrastructure of the fish nematode Huffmanela huffmani (Trichosomoididae)
}

\author{
Zdeňka Žd'árská ${ }^{1}$, David G. Huffman ${ }^{2}$, František Moravec $^{1}$ and Jana Nebesářrová ${ }^{1}$ \\ ${ }^{1}$ Institute of Parasitology, Academy of Sciences of the Czech Republic, Branišovská 31, 37005 České Budějovice, Czech \\ Republic; \\ ${ }^{2}$ Freeman Aquatic Station, Southwest Texas State University, San Marcos, Texas 78666-4616, USA
}

Key words: Nematoda, Trichosomoididae, Huffmanela, egg shell, ultrastructure

\begin{abstract}
The egg shell of Huffmanela huffmani Moravec, 1987 forms three main layers: an outer vitelline layer, a middle chitinous layer, and an inner lipid layer. The vitelline layer, forming the superficial projections of the egg shell, comprises two parts: an outer electron-dense, and an inner electron-lucid part. The chitinous layer is differentiated into three parts: an outer homogenous electron-dense part, a lamellated part, and an inner electron-dense net-like part. The lipid layer comprises an outer net-like electron-lucid part, and an inner homogenous electron-lucid part. The polar plugs are formed by electron-lucid material with fine electron-dense fibrils.
\end{abstract}

At present, the trichinelloid genus Huffmanela Moravec, 1987 comprises eight species of histozoic parasites of fishes, of which seven are known only by their characteristic eggs (Moravec 2001). The adult nematodes have been described only in the type species, Huffmanela huffmani Moravec, 1987. H. huffmani is the only representative of the genus from freshwater fishes, and parasitises centrarchids in the Upper San Marcos River, central Texas (Huffman and Moravec 1988). Advanced (larvated), dark-shelled eggs of this parasite occur frequently in masses in the swimbladders of host fishes, appearing as black spots there. The eggs are laid with thin shells and then, in the host's tissue, they increase in size somewhat and change in colour. The chitinous layer of the egg shell becomes thicker and gradually turns from colourless to brown or even black.

The ultrastructure of trichinelloid eggs has so far been studied mainly in species of the family Trichuridae, intestinal parasites of mammals (Wharton and Jenkins 1978, Preston and Jenkins 1984). Some data on the egg morphology of these tissue parasites have been published at the light microscopical level (Moravec 1987, Huffman and Moravec 1988, Moravec and Campbell 1991, Gállego et al. 1993, Moravec et al. 1998), but no data are available on the egg shell ultrastructure of trichosomoidids developing in host tissues. The present study describes, for the first time, the ultrastructure of the egg shell of a trichosomoidid parasitic in a piscine host.

\section{MATERIALS AND METHODS}

The fish Lepomis auritus (L.) infected with Huffmanela huffmani eggs were caught in the Upper San Marcos River in San Marcos, Texas, on 19 September 1999. The swimbladder wall used for the TEM study contained only fully developed eggs; neither young eggs nor adult nematodes were detected. Infected parts of the swimbladder were rinsed in saline, fixed in $3 \%$ glutaraldehyde in $0.1 \mathrm{M}$ cacodylate buffer $(\mathrm{pH} 7.2)$ at $4^{\circ} \mathrm{C}$ for $2 \mathrm{~h}$, postfixed in $1 \%$ osmium tetroxide at $4^{\circ} \mathrm{C}$ for $2 \mathrm{~h}$, dehydrated in an ethanol series and embedded in Durcupan via acetone. A series of ultrathin sections were cut using a Leica UCT ultramicrotome, double stained with uranyl acetate and lead citrate and viewed in a JEOL 1010 transmission electron microscope operated at $80 \mathrm{kV}$. Semi-thin sections were stained in toluidine blue. For SEM examination, the eggs were postfixed in $1 \%$ osmium tetroxide, dehydrated through an ethanol series and acetone, and then subjected to critical point drying. They were coated with gold and examined with a JSM-6300 scanning electron microscope at an accelerating voltage of 15 $\mathrm{kV}$.

\section{RESULTS}

In the swimbladder wall, the fully formed eggs of $H$. huffmani were localised intracellular (Figs. 3, 4, 7), extracellular, and in granulomas (1-5 eggs per granuloma) (Figs. 8-10). The eggs have a typical trichinelloid structure. The egg shell consists of three layers: an external electron-lucid vitelline layer which envelops the entire egg including the polar plugs, a middle electron-dense chitinous layer, and an inner electronlucid lipid layer. The chitinous and lipid layers do not change with age, but the vitelline layer does. At first, the vitelline layer is thin, consisting only of electronlucid material (Fig. 4). The electron-lucid vitelline layer with typical superficial projections (Figs. 1,2) later differentiates into two parts, an internal electron-lucid part and an external electron-dense part (Figs. 3, 7). Finally, both parts grow stronger (mainly in granulomas, see Figs. 8-10) and the outer part of the vitelline layer becomes more electron-dense (Figs. 8-10). 


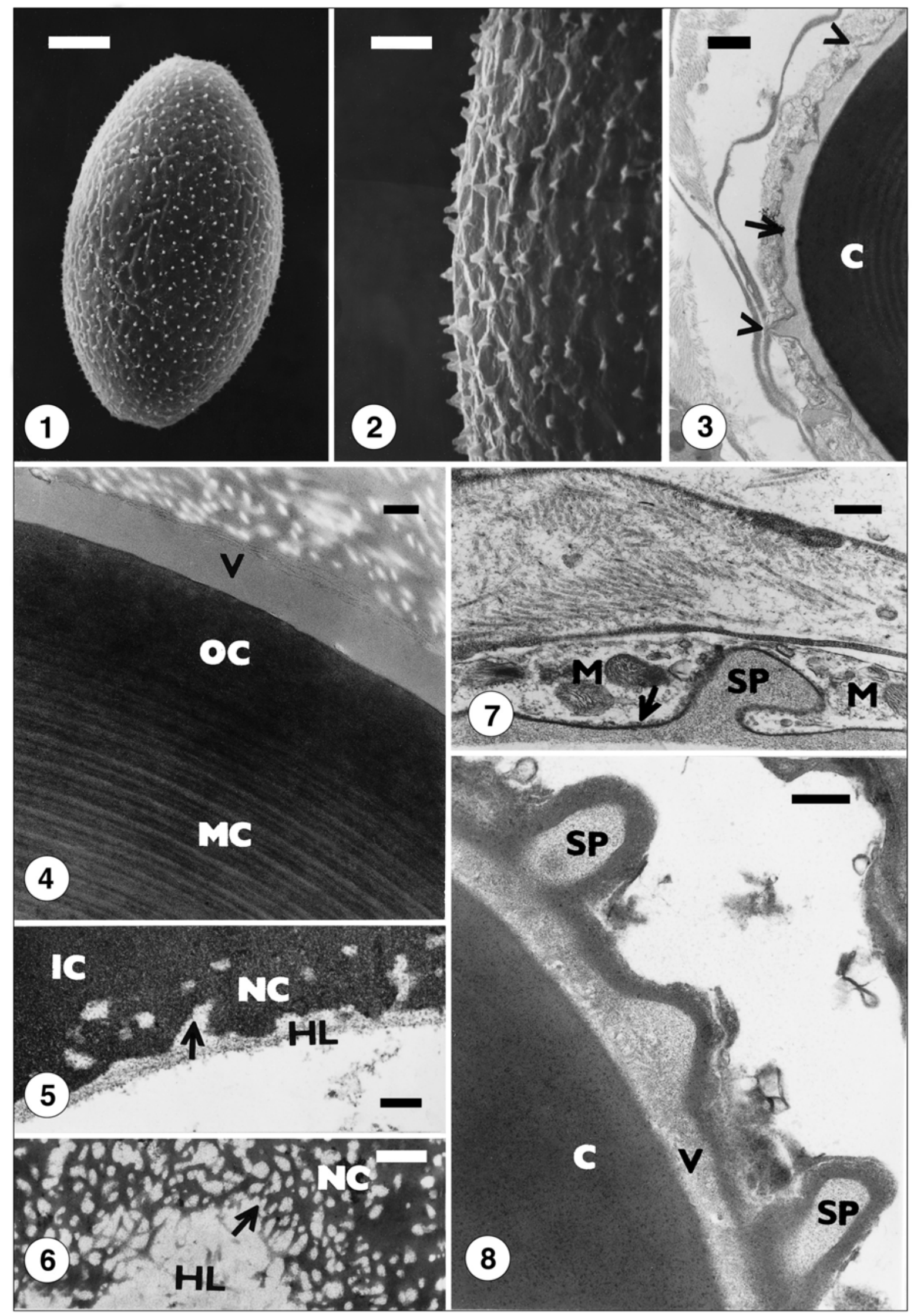




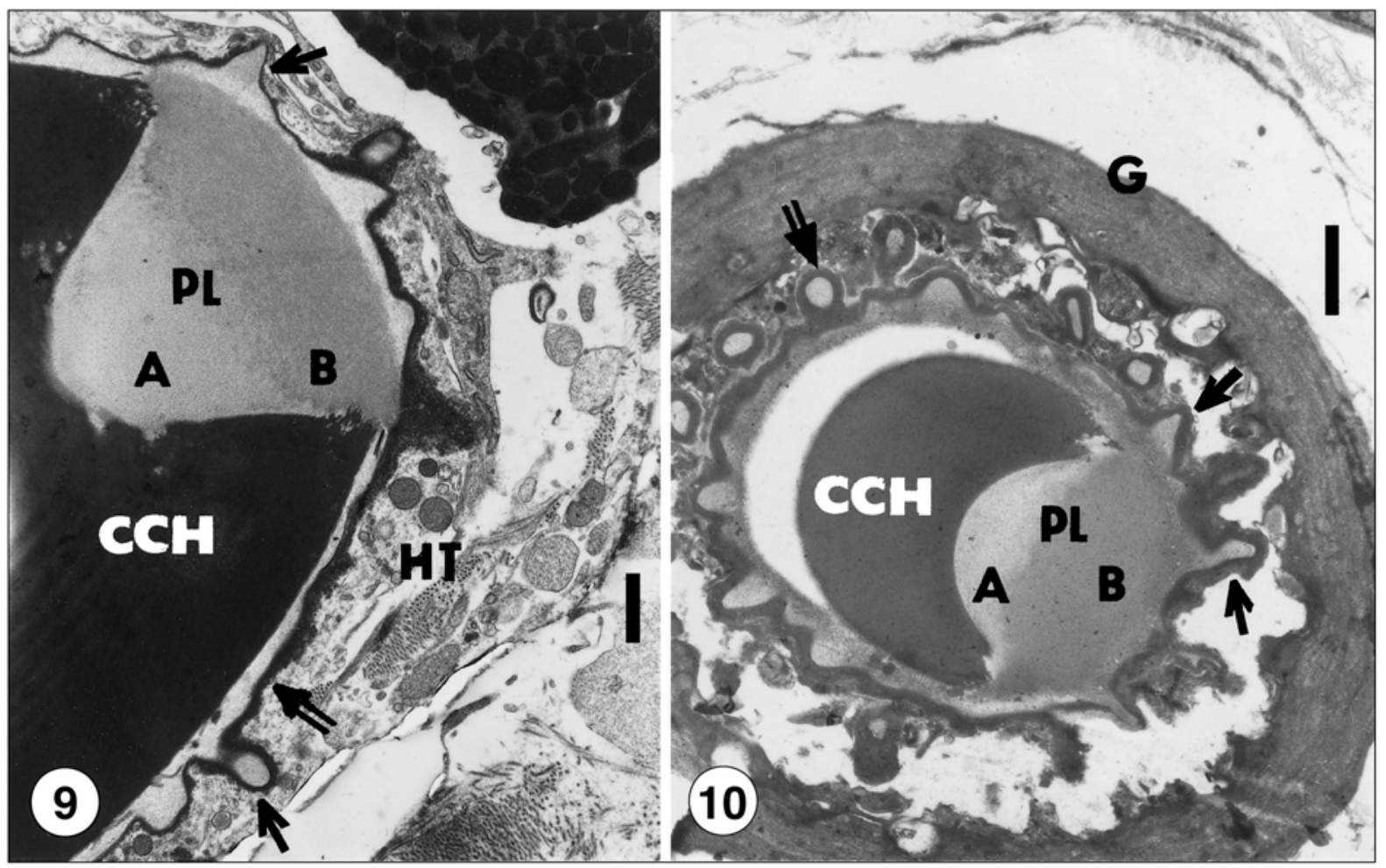

Figs. 1-8. Huffmanela huffmani eggs, scanning electron and transmission electron micrographs. Fig. 1. Egg shell surface structure. Fig. 2. Detail of vitelline layer superficial projections. Fig. 3. Vitelline (arrow) and chitinous (C) layers of egg localised intracellular in swimbladder tissue; arrowheads - superficial projections of vitelline layer. Fig. 4. Egg shell with vitelline layer (V), not differentiated into two parts, and well-visible lamellae of middle part of chitinous layer (MC); OC - outer homogenous part of chitinous layer. Fig. 5. Cross-section of net-like (arrow) and homogenous (HL) parts of electron-lucid lipid layer; IC inner homogenous part of chitinous layer; NC - net-like part of this layer. Fig. 6. Same as in Fig. 5, horizontal section; net-like part of chitinous layer (NC); net-like (arrow) and homogenous (HL) parts of lipid layer. Fig. 7. Detail of vitelline layer (arrow) and superficial projection (SP) of egg localised intracellular. Note thin electron-dense part of vitelline layer; M - host cell mitochondria. Fig. 8. Detail of vitelline layer (V) and superficial projections (SP) of egg localised in a granuloma. Note thick electron-dense part of vitelline layer; $C$ - chitinous layer. Scale bars: Fig. $1=10 \mu \mathrm{m}$; Fig. $2=3 \mu \mathrm{m}$; Fig. $3=1 \mu \mathrm{m}$; Fig. $4=200$ $\mathrm{nm}$; Figs. 5-8 $=500 \mathrm{~nm}$.

Figs. 9, 10. Huffmanela huffmani eggs, transmission electron micrographs. Fig. 9. Longitudinal section through egg shell at plug region. Note electron-lucid (A) and less electron-lucid (B) parts of plug (PL). Vitelline layer (double arrow) with superficial projections (arrows) differentiated into electron-lucid inner part and electron-dense outer part; $\mathrm{CCH}$ - collar of chitinous layer; HT - host tissue. Fig. 10. Tangential section through plug region of egg localised in a granuloma (G). Note plug (PL), differentiated in two parts (A, B), and superficial projections of vitelline layer sectioned longitudinal (arrows) and transversal (double arrow); $\mathrm{CCH}-$ collar of chitinous layer surrounding plug. Scale bars: Fig. $9=1 \mu \mathrm{m}$; Fig. $10=2 \mu \mathrm{m}$.

Simultaneously the superficial projections of the vitelline layer grow in size and become easily visible on the polar plugs (Figs. 9, 10) as well as on the remaining part of the egg (Figs. 3, 7, 8).

The middle chitinous layer consists of three parts: an external homogenous electron-dense part, a middle lamellar part (Fig. 4), and an inner electron-dense netlike part connected to the net-like part of the electronlucid lipid layer (Figs. 5, 6). The lamellae of the middle part of the chitinous layer consist of electron-dense and less electron-dense material (Fig. 4). The lipid layer is thin and electron-lucid. It consists of two parts, an exter- nal net-like part and internal homogenous part (Fig. 5). The lipid layer borders the whole inner part of the egg shell including the polar plugs.

The polar plug sits in a collar formed by the chitinous layer (Figs. 9, 10). The external part of the plug is covered by the vitelline layer, the inner part is bordered by the lipid layer. The plug consists of an electron-lucid matrix with electron-dense fibrils (Figs. 9, 10). The outer part of the plug contains more of these fibrils, thus dividing the plug into an outer (more dense) and inner layer (Figs. 9, 10). 


\section{DISCUSSION}

Trichinelloid eggs are typically oval- or barrelshaped with a plug at either end.

The present ultrastructural results of fully formed Huffmanela huffmani egg shells correspond to the general ultrastructure of the trichurid nematodes Trichuris suis (Schrank, 1788) and Trichuris muris (Schrank, 1788) studied by Wharton and Jenkins (1978) and Preston and Jenkins (1984). They differ strictly from the general ultrastructure of the capillariid nematode Calodium hepaticum (Bancroft, 1893) studied by Grigonis and Solomon (1976) and Wharton (1980). In H. huffmani, the three main egg shell layers, vitelline, chitinous and lipid, are well formed. They are distinguished from the trichurid egg shells mainly in the changes in the vitelline layer after oviposition. In $H$. huffmani, changes occur only in the vitelline layer and their superficial projections. This layer, primarily thin and electron-lucid, grows and differentiates into two layers, an outer electron-dense layer and an inner electron-lucid layer. The vitelline layer has been described earlier by Huffman and Moravec (1988) as a spinose envelope. It seems that the transparent eggs, described by these authors, represent the egg shells at the beginning of the chitin layer formation.

The observation that some eggs of $H$. huffmani were localised intracellular may suggest that the nematode $H$. huffmani is an intracellular parasite, as is Huffmanela shikokuensis Moravec, Koudela, Ogawa et Nagasawa, 1998 (see Moravec et al. 1998).

Acknowledgements. The authors wish to thank Mike Schlimgen and Bobby G. Whiteside for their help in catching fishes from the San Marcos River in Texas. Thanks are also due to Antonín Polák and Ladislava Nováková from the Laboratory of Electron Microscopy, Institute of Parasitology, ASCR, in České Budějovice, and to Ondřej Kropík from the Laboratory of Helminthology of the same institute for their technical assistance. This study was supported by grant No. A6022901 from the Grant Agency of the Czech Republic.

\section{REFERENCES}

GÁlLEGO J., RIERA C., PORTÚS M. 1993: Huffmanela sp. eggs (Nematoda: Trichosomoididae), as a human spurious parasite in a child from Barcelona (Spain). Folia Parasitol. 40: 208-210.

GRIGONIS G.J., Jr., SOLOMON G.B. 1976: Capillaria hepatica: fine structure of egg shell. Exp. Parasitol. 40: 286-297.

HUFFMAN D.G., MORAVEC F. 1988: First description of adult Huffmanela huffmani Moravec, 1987 (Nematoda: Trichosomoididae) from the swimbladder of centrarchid fishes of the upper San Marcos River, central Texas. Folia Parasitol. 35: 227-234.

MORAVEC F. 1987: Revision of Capillariid Nematodes (Subfamily Capillariinae) Parasitic in Fishes. Studie ČSAV No. 3. Academia, Praha, 141 pp.

MORAVEC F. 2001: Trichinelloid Nematodes Parasitic in Cold-Blooded Vertebrates. Academia, Praha, 429 pp.
MORAVEC F., CAMPBELL B.G. 1991: A new Huffmanela species, H. schouteni sp. n. (Nematoda: Trichosomoididae) from flying fishes in Curaçao. Folia Parasitol. 38: 29-32.

MORAVEC F., KOUDELA B., OGAWA K., NAGASAWA K. 1998: Two new Huffmanela species, H. japonica n. sp. and $H$. shikokuensis n. sp. (Nematoda: Trichosomoididae), from marine fishes in Japan. J. Parasitol. 84: 589593.

PRESTON C.M., JENKINS T. 1984: Trichuris muris: structure and formation of egg shell. Parasitology 89: 263273.

WHARTON D.A. 1980: Nematode egg-shells. Parasitology 81: 447-463.

WHARTON D.A., JENKINS T. 1978: Structure and chemistry of the egg-shell of a nematode (Trichuris suis). Tissue Cell 10: 427-440.

Accepted 10 January 2001 